\title{
Interface entre Missão e Propósito das Empresas Brasileiras B Corporations
}

\author{
Interface between Mission and Purpose of Brazilian $B$ Corporations
}

\author{
Francisca Noeme Moreira de Araújo 1 \\ Wendy Karla Medeiros de Souza Bezerra ${ }^{2}$ \\ Kleber Cavalcanti Nóbrega ${ }^{3}$ \\ Fernanda Joyce da Rocha Neves ${ }^{4}$ \\ Euller de Sousa Mendonça ${ }^{5}$
}

\begin{abstract}
Resumo
Esta pesquisa analisa as interfaces entre as declarações de Missão e de Propósito de empresas com certificação $B$ Corporations do Brasil, a partir da seguinte questão: quais são as interfaces entre a Missão e o Propósito em empresas brasileiras que possuem a certificação B Corporations? A missão é um importante componente da identidade organizacional e representa a razão de existir de uma empresa. É considerada como uma ferramenta de comunicação da empresa com o mercado e com o público interno. O propósito emergiu como fortalecimento da missão; além disso, apoia a condução da implementação estratégica para o alcance da visão e da vivência dos valores. O público pesquisado é composto pelas empresas certificadas $B$ Corporation do Brasil. Em relação aos procedimentos metodológicos, foi conduzida uma pesquisa nos websites dessas empresas. Para avaliação da declaração de missão foram analisadas 11 categorias e para a avaliação da declaração de propósito foram analisadas 6 categorias. Com o uso de uma escala, analisou-se a presença ou ausência das categorias da missão e do propósito, respectivamente, na declaração de Missão e na declaração de propósito de empresas certificadas B Corporation, do Brasil. Os resultados mostram que, quando utilizadas de forma consistente, essas categorias geram uma consonância entre as duas mensagens. O estudo contribui para as pesquisas em comunicação organizacional e relação com stakeholders.

Palavras-Chave: Declaração de missão. Propósito organizacional. Empresas B corporation. Comunicação organizacional.
\end{abstract}

\footnotetext{
${ }^{1}$ Universidade Potiguar - UnP, Brasil. ORCID: https://orcid.org/0000-0003-2124-8307

E-mail: noeme_moreira@hotmail.com

2 Universidade Potiguar - UnP, Brasil. ORCID: https://orcid.org/0000-0001-8528-5479

E-mail: wendy.bezerra@gmail.com

${ }^{3}$ Universidade Potiguar - UnP, Brasil. ORCID: https://orcid.org/0000-0002-2103-4379

E-mail: kleber@klebernobrega.com.br

${ }^{4}$ Universidade Potiguar - UnP, Brasil. ORCID: https://orcid.org/0000-0001-5676-7348

E-mail: fernandarochasm@gmail.com

${ }^{5}$ Universidade Potiguar - UnP, Brasil. ORCID: https://orcid.org/0000-0001-5948-7093

E-mail: eullesousa@gmail.com
} 


\begin{abstract}
The present research analyses the interface between the Mission and the Purpose statements of companies of Brazil with B Corporation certification from the following question: what are the interfaces between Mission and Purpose in Brazilian companies with B Corporation certification? Mission is an important component of the organizational identity and it represents the raison d'être of a company. It is considered as a communication tool of the company with the market and the internal public. Purpose has emerged as the mission strengthening; in addition, it supports the conduction of strategic implementation in order to reach vision and value experiencing. The pubic studied is made up by B corporations of Brazil. Concerning the methodological procedures, a research was carried out on the websites of these companies. 11 categories were analyzed for the mission statement evaluation and 6 categories were analyzed for the purpose statement evaluation. By using a scale, the presence and the absence of mission and purpose categories were respectively analyzed in the Mission and in the purpose statements of certified B Corporations of Brazil. The results show that these categories generate consonance between the two messages when they are used in a consistent way. The study has contributed to the researches in organizational communication and stakeholders relations.
\end{abstract}

Keywords: Mission statement. Organizational purpose. B Corporation. Organizational communication.

$$
* * *
$$

\title{
1 Introdução
}

O advento da globalização e o surgimento de novas tecnologias proporcionaram mudanças ao mundo moderno. No que se refere às organizações, essas mudanças impulsionaram a competitividade e permitiram acesso aos diferentes mercados. Nesse cenário, os gestores das organizações sentiram a necessidade de traçar estratégias visando o diferencial competitivo (Thompson Jr, Strickland II, \& Gamble 2008).

O estudo da missão organizacional emergiu por volta da década de 1980 (Machado, 2003; Mussoi, Lunkes, \& Silva, 2011; Stallworth, 2008), período em que as organizações passaram a ter necessidade de se diferenciarem e causarem nas pessoas um senso de pertencimento (compradores e funcionários). Para atingir esses objetivos, a missão deve ser clara e envolver indivíduos e grupos de dentro de uma empresa, independentemente do nível hierárquico (Bart, 2006; King, Case, \& Premo, 
2012; Stallworth, 2008). A declaração de missão também funciona como uma ferramenta de comunicação da empresa com o ambiente externo (Stallworth, 2008). Embora o estudo da missão ultrapasse 30 anos, o tema ainda é negligenciado no âmbito empresarial, tendo em vista que algumas empresas apresentam declarações de missão de baixa consistência (Araújo, 2016; Bart, 2006), a qual se refere ao texto que deixa explícito o motivo da existência da organização e proporciona um senso de direção organizacional.

Como apoio à missão organizacional, emergiu posteriormente no ambiente empresarial, a utilização de declaração do propósito organizacional. A declaração do propósito organizacional não substitui a declaração de missão e a dos valores organizacionais, pois o papel do propósito é ser um "guia" ou "condutor" para as pessoas em prol de um objetivo comum, com o foco na identidade da empresa e na coletividade, ou seja, relaciona-se ao modo como a empresa pretende contribuir para a sociedade, sem negligenciar o lucro (Araújo, 2016; Khalifa, 2012; Mintzberg, 2000; Ready \& Truelove, 2011).

Parte das empresas brasileiras passou a utilizar a declaração do propósito. Em 2016, Araújo realizou uma pesquisa buscando analisar o propósito das empresas de serviços consideradas pelo Anuário “as Melhores Empresas para Trabalhar, publicado pela Revista Exame em 2015. Ela identificou apenas uma empresa com o propósito declarado. Desta forma, o estudo do propósito no meio acadêmico e empresarial é de grande relevância.

Considerando a aplicabilidade do propósito nas organizações, existe um movimento global denominado $B$ Corporations ou simplesmente $B$-corp, o qual tem como finalidade certificar empresas com fins lucrativos que preocupam-se em oferecer produtos e serviços que contribuam para o meio ambiente e o bem-estar social, além da promoção de lucro para acionistas.

Esta pesquisa analisa as interfaces entre as declarações de Missão e de Propósito de empresas $B$ Corporations; desta, forma questiona-se: quais são as interfaces entre a Missão e o Propósito em empresas brasileiras que possuem a certificação $B$ Corporations? De forma geral, esta pesquisa se 
justifica pela relevância do tema para os estudos de comunicação empesarial e relações com stakeholders. Quanto aos procedimentos de pesquisa, foi realizada pesquisa documental para analisar a declaração de missão organizacional e a de propósito organizacional e identificar se existe relação entre a Missão e o Propósito.

\section{Referencial Teórico}

\subsection{Declaração da Missão Organizacional}

A missão organizacional é um elemento que compõe a identidade organizacional e é através dela que uma empresa comunica a razão de sua existência. O estudo da missão como direcionador estratégico das organizações iniciou-se na década de 1980 (Machado, 2003; Mussoi, Lunkes, \& Silva, 2011). E, desde então, vem sendo utilizada como meio de comunicação corporativa entre a empresa e os seus stakeholders (Irigaray et al. 2014; Stallworth, 2008). De acordo com Mintzberg et al., (2000), o que distingue uma organização da outra é a sua missão, pois duas organizações podem ter o mesmo negócio, mas nunca poderão ter a mesma missão, tendo em vista que a missão declara a finalidade de existência de uma organização, a tornando única (Drucker, 2006).

Todos os conceitos definidos pelos autores citados convergem para a declaração de uma missão condizente com a essência da empresa (Tabela 1). Durante décadas de estudos dedicados à missão organizacional, o conceito passou por transformações e veio sendo ampliado para abranger não só o papel da organização na sociedade ou a razão de sua existência, mas também para envolver outros aspectos relativos ao objetivo e à imagem organizacional. Mussoi, Lunkes, \& Silva (2011) afirmam que a missão deve revelar a imagem da organização e nortear as decisões estratégicas. Desta forma, a missão pode ser considerada como uma bússola que norteia os rumos de uma organização. A Tabela 1 apresenta uma síntese do conceito de missão. 
Tabela 1. Conceitos de Missão

\begin{tabular}{|c|c|}
\hline Autor & Conceituação \\
\hline $\begin{array}{l}\text { Pearce et al. } \\
\quad(1982)\end{array}$ & $\begin{array}{l}\text { A missão deve ser objetiva e capaz de ser avaliada periodicamente; o autor } \\
\text { defende que elementos tais como o tipo de produto que é ofertado, o } \\
\text { mercado atuante ou consumidores que atende, bem como a tecnologia } \\
\text { empregada para a execução dos processos, a filosofia empresarial, } \\
\text { lucratividade, imagem desejada e identidade própria devem ser } \\
\text { considerados na formulação da missão. }\end{array}$ \\
\hline $\begin{array}{l}\text { Campbell } \\
\text { (1997) }\end{array}$ & $\begin{array}{l}\text { A missão deve ser atraente aos consumidores, definir o posicionamento } \\
\text { estratégico da empresa que engloba os valores. Descreve os padrões de } \\
\text { comportamento dos funcionários e avalia o reflexo da missão; ainda explica } \\
\text { que, quando a missão não é compreendida, causa consequências adversas. }\end{array}$ \\
\hline $\begin{array}{l}\text { Mullane } \\
(2002)\end{array}$ & A missão deve ser Mensurável e adaptável \\
\hline $\begin{array}{l}\text { Sufi e Lyons } \\
\quad(2003)\end{array}$ & $\begin{array}{l}\text { Defendem a utilização dos elementos: relacionamento com clientes, } \\
\text { produto/serviço, tecnologia, mercado atuante, estratégias de sobrevivência e } \\
\text { de crescimento, rentabilidade, filosofia, imagem organizacional, liderança, } \\
\text { partes interessadas e responsabilidade social na declaração da missão. O } \\
\text { autor ainda defende a importância da clareza na definição de uma missão. }\end{array}$ \\
\hline $\begin{array}{c}\text { David e } \\
\text { David (2003) }\end{array}$ & $\begin{array}{l}\text { A missão deve ser consistente, focada e possuir elementos direcionadores; } \\
\text { sugerem que uma missão eficaz deve incluir nove elementos: clientes, } \\
\text { produtos/serviços, localização geográfica, tecnologia, estratégia de } \\
\text { crescimento, lucro, filosofia/valores, funcionários e competência } \\
\text { organizacional. }\end{array}$ \\
\hline Bart (2006) & $\begin{array}{l}\text { A missão deve ser capaz de conseguir criar uma aprendizagem coletiva, que } \\
\text { consiga se fazer entender pelos funcionários que compreendam o propósito } \\
\text { da empresa, o motivo de sua existência e a sua meta. A missão deve ser } \\
\text { clara e direcionada aos funcionários e aos consumidores, além de ser algo } \\
\text { que faça parte do dia a dia da empresa. }\end{array}$ \\
\hline $\begin{array}{l}\text { Biloslavo e } \\
\text { Lynn (2007) }\end{array}$ & $\begin{array}{l}\text { A missão consistente deve possuir elementos que representem as partes } \\
\text { interessadas, tais como: referência à empresa, cliente, produtos/serviços, } \\
\text { pessoas e desenvolvimento organizacional. }\end{array}$ \\
\hline $\begin{array}{l}\text { Cochran et al } \\
(2008)\end{array}$ & $\begin{array}{l}\text { A missão deve servir principalmente para guiar gestores no } \\
\text { desenvolvimento de uma missão consistente. }\end{array}$ \\
\hline
\end{tabular}

Fonte: Araújo (2016, p. 28)

Nessa perspectiva, a missão passa a ser vista como all-inclusive e possui três pilares fundamentais: compromisso que reflita autenticidade da missão; valor significativo e inspirador para melhorar a capacidade da organização, e uma causa nobre para dar significado a todos da empresa de tal forma que estejam dispostos a gastarem suas energias na perseguição dos objetivos (Khalifa, 2012). 


\subsection{Propósito Organizacional}

O conceito de propósito organizacional surge da perspectiva de unir-se à missão, à visão e aos valores de forma a complementar esses elementos, e não substituí-los. O propósito organizacional direciona a construção de uma missão inspiradora, que mobilize os funcionários para sua concretização (Ready \& Truelove, 2011), e pode ser definido como relacionado com a razão de ser da organização, ou seja, revela o motivo fundamental para a existência de uma organização (Mintzberg, 2000). O propósito nasce da essência da empresa; ele é único e não permite ser copiado por outra empresa (benchmarking).

O propósito visa direcionar a realização do trabalho em equipe, pois o funcionário entende que suas ações geram mudanças e envolvimento que vão além da realização do seu trabalho, exigindo que o funcionário se preocupe com o resultado de seu trabalho e como este pode afetar o todo. A definição do propósito organizacional auxilia no engajamento dos funcionários, pois o propósito foca o efeito, a estratégia e os valores, devendo traduzir os padrões de comportamento através da filosofia da empresa (Khalifa, 2012).

O propósito auxilia na definição da estratégia organizacional, pois uma empresa que possui um propósito definido sabe aonde quer chegar e o que é necessário fazer para isso (Ready \& Truelove, 2011). O propósito relaciona-se com o alcance de resultados. É criado de dentro da organização para fora; por isso, deve ser autêntico (Khalifa, 2012). Autenticidade de propósito significa originalidade, e essa é determinante para uma organização que pretende ter um propósito firmemente estabelecido. Uma empresa que tem propósito pode potencializar o seu impacto na sociedade, trabalhar focada no valor no sentido da sustentabilidade organizacional, bottom line, bem-estar dos funcionários e da sociedade como todo (Champy \& Nohria, 2000).

Khalifa (2012) relaciona três pilares fundamentais na definição do propósito. O primeiro corresponde à reflexão da autenticidade da missão, o 
segundo a um valor significativo e à capacidade da organização trabalhar com inspiração e o terceiro corresponde à definição de um propósito digno que dê significado ao trabalho dos funcionários (Ellsworth, 2002; George, 2003; Khalifa, 2012).

O propósito é a forma como a empresa deixa sua contribuição para a sociedade e o meio ambiente (Khalifa, 2012). Grandes empresas são movidas por propósito, considerando o lucro como consequência de tudo o que é realizado e visando a geração de valor para as partes interessadas. Empresas com propósito são valorizadas, reconhecidas e admiradas pelos seus stackholders (Sisodia, 2009).

\subsection{B Corporation - Empresas Benéficas}

No ano de 2006, nos Estados Unidos e no Canadá, emergiu no meio empresarial um movimento chamado Movimento B (B Corporation, 2019) que chegou ao Brasil em 2013. Este movimento é composto por empresas que possuem fins lucrativos, mas buscam gerar valor para a sociedade além de retorno aos acionistas. O interesse pela busca da Certificação B é voluntário e exige que a empresa cumpra alguns pré-requisitos necessários para a certificação; após a avaliação, as empresas recebem a certificação $B$ Corporation, que significa Empresas B, e o B significa benéficas.

De acordo com Gilbert (2010), o foco das B Corps é na certificação das empresas e não nos produtos. $\mathrm{O}$ autor destaca que ao fazer isso impede que a empresa tenha produtos certificados e, mesmo assim, realize práticas prejudiciais ao meio ambiente ou à sociedade. As $B$ Corps são empresas que usam o poder de seus negócios para solucionar problemas sociais e ambientais e se baseiam na filosofia de ser a melhor empresa para o mundo e não ser a melhor empresa do mundo.

O Movimento B Corp propõe incluir a dimensão socioambiental como parte da missão final das organizações (Comini, 2014). Porter e Kramer (2011) definem que uma B Corp precisa ter um propósito definido e que este deve ser voltado para criação de valor compartilhado. Uma comunidade 
próspera contribui para a prosperidade das organizações e, desta forma, todos saem ganhando.

Segundo o Website B Corporation (2018), os benefícios de se tornar uma B-Corp incluem a capacidade de atrair e reter talentos, atrair investidores e parceiros, ter diferencial competitivo e consequentemente ter uma imagem positiva diante da comunidade. As empresas são avaliadas a partir das variáveis: desempenho social e ambiental, transparência pública e responsabilidade legal.

\section{Metodologia}

A pesquisa se enquadra como exploratória. Foi conduzida através de análise documental, baseada em declarações de missão das empresas brasileiras certificadas pelo Sistema B. O acesso à declaração da missão das empresas foi realizado por meio das páginas dessas empresas na internet, ou seja, por uma pesquisa documental na Internet (websites das empresas).

As variáveis do estudo foram definidas a partir da consolidação de três dimensões de pesquisa: conceito de missão, de propósito e de B-Corp. Para cada dimensão, foram definidas categorias de análise. Essas categorias de análise foram definidas ex ante, a partir do referencial teórico e dos autores citados nas Tabelas 1 e 2, levando em consideração o que eles definem como relevantes para cada dimensão.

A Missão é composta por 11 categorias: acionista, relacionamento com clientes, relacionamento com funcionários, relacionamento com fornecedores, relacionamento com a sociedade, serviços/produto, responsabilidade socioambiental, tecnologia, localização geográfica e rentabilidade, conforme Pearce et al. (1982), Campbell (1992), Mullane (2002), Sufi e Lyons (2003), David e David (2003), Bart (2006), Cochran et al (2008). No que se refere ao propósito, foram identificadas 6 categorias: sociedade, valor/filosofia, sustentabilidade, bottom line, bem-estar/felicidade dos funcionários e estratégia organizacional, conforme o estudo de Khalifa (2012). 
Como ferramenta de avaliação, foi utilizada uma escala que visa avaliar o grau de frequência de cada dimensão referente à declaração da missão e do propósito da empresa, quando disponível. A escala contemplou as seguintes possibilidades de avaliação, conforme mostra a Tabela 2.

Tabela 2. Escala utilizada na análise das declarações de missão das empresas B Corp

\begin{tabular}{c|c}
\hline \multirow{2}{*}{ Escala } & \multicolumn{1}{c}{ Correspondência } \\
\hline $\mathbf{1}$ & Sem referência direta ao assunto, e sem qualquer referência indireta \\
\hline $\mathbf{2}$ & Sem referência direta ao assunto, mas com referência indireta \\
\hline $\mathbf{3}$ & Nenhuma citação direta ao assunto, mas com referência direta \\
\hline $\mathbf{5}$ & Sem referência direta ao assunto, nem referência direta \\
\hline $\mathbf{6}$ & Com referência indireta ao assunto, com referência \\
\hline $\mathbf{7}$ & Com citação direta ao assunto, sem referência \\
\hline & Com citação direta ao assunto e referência direta \\
& Muito baixa $-1,0 \leq \mathrm{X} \leq 2,1$ \\
& Baixa $-2,2 \leq \mathrm{X} \leq 3,4$ \\
& Moderada $-3,5 \leq \mathrm{X} \leq 5,7$ \\
& Alta $-5,8 \leq \mathrm{X} \leq 6,9$ \\
& Muito Alta $-\mathrm{X}=7,0$ \\
& \\
& \\
&
\end{tabular}

Fonte: adaptado de Araújo (2016, p. 45)

Os dados foram analisados através da observação das médias e frequências dos elementos através do grau de adesão da missão aos elementos teóricos, presença de variáveis do propósito e comparativo entre as médias das declarações de missão e propósito. A pontuação utilizada, varia de 1 a 7, corresponde ao grau em que a missão formalizada atende aos elementos do estudo. Para cada pontuação, verifica-se uma correspondência à variável relacionada, sendo que a primeira linha refere-se à citação ao variável, e a segunda linha consiste de uma análise secundária, em que procurou-se avaliar se, independente da citação, havia alguma referência ao assunto. Foi considerado que havia citação quando uma das palavras do atributo era citada explicitamente na declaração de missão. Por outro lado, em algumas oportunidades, poderia haver menção ao assunto, ainda que não houvesse citação explícita do atributo. A partir desta análise foi aplicada a escala definida por Araújo (2016) (Tabela 2). 


\section{Resultados}

Nesta seção, são apresentados e discutidos os resultados obtidos na pesquisa. Interface entre Missão e Propósito. Todas as análises foram realizadas, primeiramente, através de Análise de Conteúdo, complementada por Análise de Frequência.

\subsection{Análise da Declaração de Missão}

No que se refere à Missão, inicialmente foi realizada a análise individualmente das declarações de missão, começando pela avaliação da extensão e dos elementos presentes. Segundo Bart (2006), não existe nenhuma regra para definir o tamanho de uma missão ideal; no entanto, destaca-se a importância da definição de uma missão coerente e completa. $\mathrm{O}$ autor alerta quanto à definição de declaração de missão muito extensa ou muito curta, pois, em ambas as situações, poderá comprometer o entendimento da mensagem transmitida.

De acordo com a análise realizada, foi identificado que o tamanho médio das declarações de missão das empresas analisadas é de 23 palavras. A declaração de missão mais extensa contém 80 palavras e pertence à empresa Cause, seguida da empresa Triciclo com 72 palavras. A declaração mais curta contém 4 palavras e pertence à empresa Resolv Já, seguida das empresas Giltec e SITAWI, ambas com 6 palavras. Na análise de cada declaração de missão, identificou-se que as declarações de missão mais extensas apresentam múltiplas sentenças, o que pode levar a falhas na interpretação e no entendimento das mesmas (BART, 2006). Já as empresas que possuem declarações de missão compostas de até 6 palavras não fazem referência nem mesmo ao segmento em que a empresa atua.

Desta forma, vale ressaltar que tanto uma declaração de missão extensa quanto uma extremamente objetiva podem proporcionar falha na comunicação da mensagem que a empresa deseja transmitir na intenção de deixar claro a sua razão de existir. Ao analisar a presença das categorias que compõem a missão, buscou-se identificar quais categorias são mais frequentes. Conforme dados da Tabela 3, a média geral referente à utilização dos elementos da missão nas declarações de missão das empresas estudadas foi de 2,4. De forma geral, esta média é considerada baixa, levando em consideração os critérios de análise adotados no 
instrumento de pesquisa. O elemento mais utilizado na declaração de missão é "serviços/produto" (19,19\%), seguido de "responsabilidade socioambiental" (15,09\%) e "responsabilidade com a sociedade" (14,44\%). A frequência da utilização desses elementos é especialmente pertinente ao universo de empresas estudadas, tendo em vista os pilares propostos pelo sistema B-Corp, que são o desempenho social e o ambiental, transparência pública e responsabilidade legal. Os elementos menos citados foram "filosofia/imagem organizacional (4,36\%) e o "posicionamento estratégico" $(3,77 \%)$.

Tabela 3. Frequência dos elementos citados nas declarações de missão

\begin{tabular}{l|c|c}
\multicolumn{1}{c|}{ Elementos } & Média & Percentual \\
& & \\
\hline Serviços/produto & 5,1 & $19,2 \%$ \\
\hline Responsabilidade Socioambiental & 2,8 & $10,4 \%$ \\
\hline Relacionamento com a sociedade & 3,2 & $12,0 \%$ \\
\hline Tecnologia & 4,0 & $15,1 \%$ \\
\hline Relacionamento com clientes & 1,0 & $3,8 \%$ \\
\hline Rentabilidade & 3,8 & $14,4 \%$ \\
\hline Relacionamento com Funcionários & 1,2 & $4,4 \%$ \\
\hline Localização geográfica & 1,3 & $5,0 \%$ \\
\hline Acionista & 1,6 & $6,1 \%$ \\
\hline Filosofia/Imagem Organizacional & 1,3 & $5,0 \%$ \\
\hline Posicionamento Estratégico & 1,2 & $4,65 \%$ \\
\hline Total & 26,5 & $100 \%$ \\
\hline
\end{tabular}

\subsection{Análise Do Propósito}

A Tabela 4 mostra a média dos elementos utilizados nas declarações de propósito analisadas. $\mathrm{O}$ estudo do propósito emergiu nos últimos tempos com a intenção de fortalecer a vivência da missão organizacional. Ou seja, o propósito complementa a missão, não a substitui (Khalifa, 2012). Desta forma, a partir da declaração do propósito e da literatura que define o conceito e elementos, foi realizada a análise da presença dos elementos do propósito na declaração de propósito das empresas estudadas. 
Tabela 4. Frequência dos elementos citados nas declarações de propósito

\begin{tabular}{l|c|c}
\multicolumn{1}{c|}{ Elementos } & Média & Percentual \\
\hline Sociedade & 2,4 & $16,0 \%$ \\
\hline Valor/Filosofia Organizacional & 2,3 & $15,6 \%$ \\
\hline Sustentabilidade & 3,1 & $21,0 \%$ \\
\hline Bottom line & 2,9 & $19,7 \%$ \\
\hline Felicidade dos Funcionários & 1,2 & $8,1 \%$ \\
\hline Estratégia Organizacional & 2,9 & $19,7 \%$ \\
\hline Total & 14,7 & $100 \%$ \\
\hline
\end{tabular}

Conforme mostra a Tabela 2, o elemento do propósito mais citado nas declarações de propósito das empresas estudadas é a categoria "sustentabilidade" (3,1), seguida de "bottom line" e de "estratégia organizacional", que obtiveram a mesma média $(2,9)$. "Bem-estar/Felicidade dos funcionários" foi a categoria menos citada dentre as declarações analisadas $(1,2)$.

\subsection{Interface entre Missão e Propósito}

Após realizar análise das dimensões missão e propósito, buscou-se identificar se existe relação entre essas duas dimensões a partir das médias obtidas por elemento. Para efeito deste estudo, foram definidos três grupos. O agrupamento permite unificar dados em grupos considerados mais homogêneos a partir de características similares. O Grupo 1 é composto por empresas que possuem apenas a missão declarada, total de 45 empresas. $\mathrm{O}$ Grupo 2 é composto por empresas que possuem apenas o propósito declarado, total de 4 empresas. E o Grupo 3 é composto por empresas que declaram tanto a missão quanto o propósito, total de 13 empresas. A Tabela 5 demonstra as médias obtidas a partir das análises.

Como pode-se observar na dimensão missão, de modo geral, as empresas pertencentes ao Grupo 1 obtiveram médias mais elevadas, exceto nos elementos serviços/produtos e relacionamento com clientes. No que se refere ao propósito, o Grupo 3 contém empresas que, de modo geral, apresentam maior frequência ao utilizar os elementos propostos. 
Tabela 5. Média por elemento: Missão e Propósito

\begin{tabular}{|c|c|c|c|c|c|c|c|c|c|c|c|c|c|c|c|c|c|}
\hline \multicolumn{12}{|c|}{ MISSÃO } & \multicolumn{6}{|c|}{ PROPÓSITO } \\
\hline & 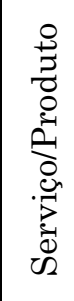 & 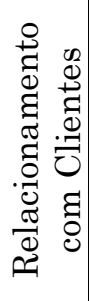 & 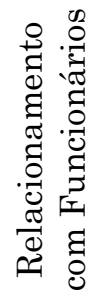 & 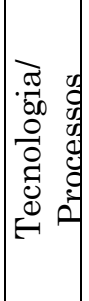 & 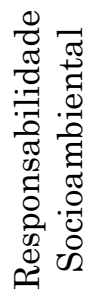 & 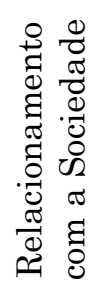 & 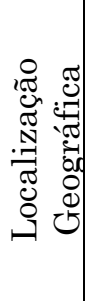 & 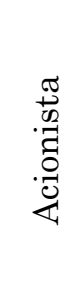 & 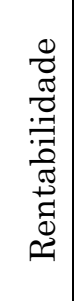 & 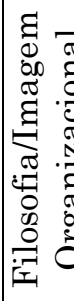 & 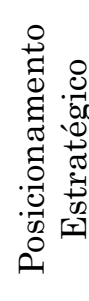 & $\begin{array}{l}0 \\
\frac{\pi}{0} \\
0 \\
0 \\
0 \\
0 \\
0 \\
0\end{array}$ & 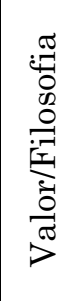 & 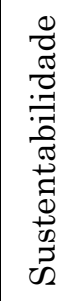 & 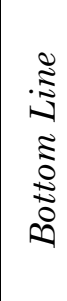 & 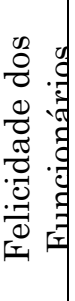 & 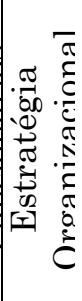 \\
\hline Gru & 5,0 & 2,7 & 1,4 & 3,2 & 4,3 & 4,2 & 1,4 & 1,3 & 1,7 & 1,1 & 1,0 & 0,0 & 0,0 & 0,0 & 0,0 & 0,0 & 0,0 \\
\hline Grupo 2 & 0,0 & 0,0 & 0,0 & 0,0 & 0,0 & 0,0 & 0,0 & 0,0 & 0,0 & 0,0 & 0,0 & 1,5 & 2,5 & 3,5 & 3,5 & 1,0 & 1,3 \\
\hline Grupo 3 & 5,3 & 2,9 & 1,0 & 2,9 & 3,1 & 2,6 & 1,0 & 1,0 & 1,5 & 1,3 & 1,0 & 2,6 & 2,2 & 2,9 & 2,8 & 1,3 & 3,5 \\
\hline
\end{tabular}

Em seguida, foi realizada uma análise comparativa entre a média geral dos elementos da missão e do propósito envolvendo os três grupos, objetivando identificar se existe interface entre as declarações de missão com as declarações de propósito. A Figura 1 demonstra os resultados obtidos.

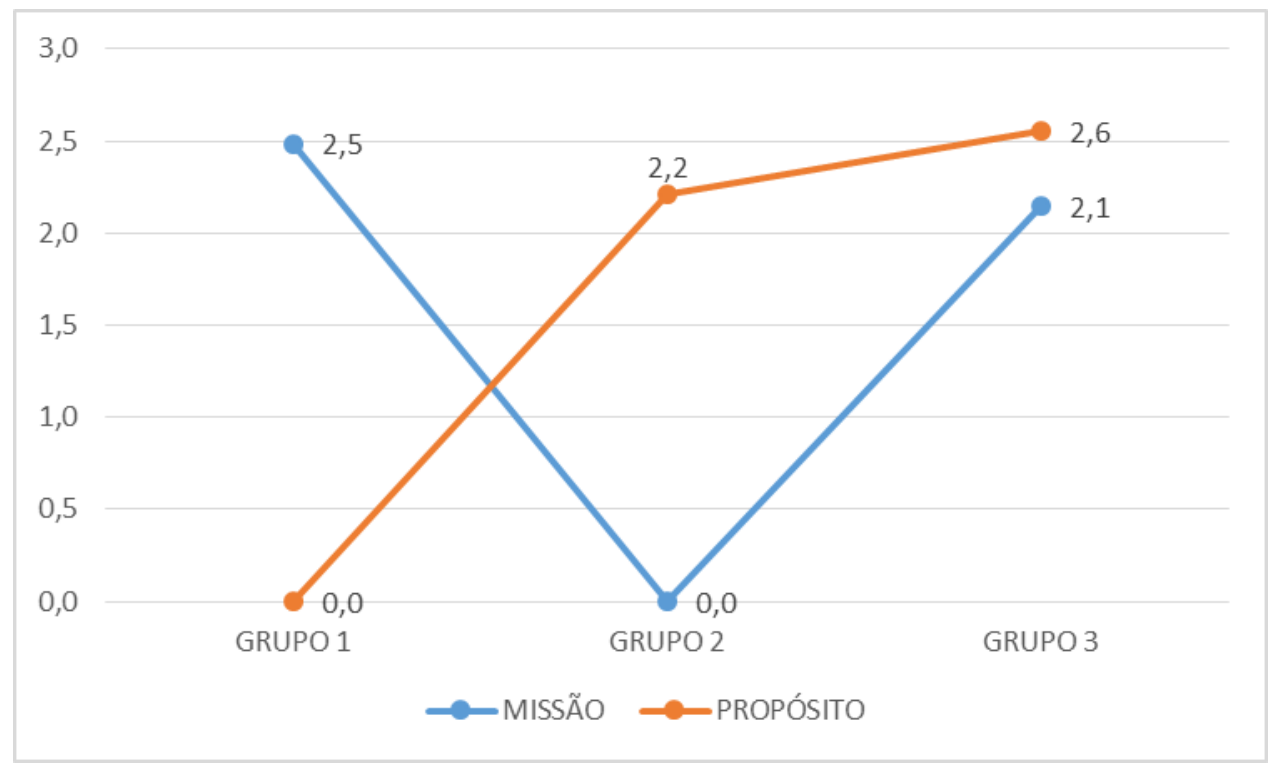

Figura 1. Interface Missão e Propósito.

Considerando a avaliação das médias como muito baixa, baixa, moderada, alta e muito alta, pode-se afirmar que, no que se refere à missão, as empresas inseridas no Grupo 1 possuem a média geral mais elevada que as empresas inseridas no Grupo 3. Sendo a média das empresas do Grupo 1 considerada baixa e a das empresas do grupo 3 , muito baixa. 
No que se refere à declaração do propósito, as empresas inseridas no Grupo 2 possuem média inferior às empresas integrantes do grupo 3; no entanto, ambas as médias são consideradas baixas. Vale ainda salientar que, em relação à missão, as empresas do Grupo 2 não fazem nenhuma declaração de missão e as do Grupo 1 não fazem nenhuma declaração do propósito, obtendo zero nas duas avaliações. É importante ainda destacar que os Grupos 2 e 3 foram os que concentraram o menor número de empresas.

No que se refere à interface entre missão e propósito, identificou-se que entre as empresas que estão inseridas no Grupo 3, as quais possuem missão e propósito declarados, existe uma aproximação das médias da declaração de missão e do propósito. No entanto, a pesquisa mostra resultado divergente, tendo em vista que o Grupo 1 possui apenas missão declarada e obteve a maior média, contrariando o que afirma Khalifa (2012); ele defende que o propósito existe como complementar à missão organizacional.

De modo geral, conforme mostra o Gráfico 1, é possível identificar a interface entre missão e propósito especificadamente em empresas que compõem o grupo 3 , tendo em vista que essas apresentam um quantitativo maior das categorias pesquisadas.

\section{Considerações Finais}

O tema declaração de missão organizacional foi amplamente discutido no meio acadêmico, desde os anos 1980. Essa declaração tornou-se uma prática empresarial desde então. Porém, esta pesquisa mostrou que existem problemas nas declarações de missão empresarial, quando consideradas as categorias propostas pelo debate acadêmico para uma declaração eficaz de missão organizacional. Outro tema abordado, nesta pesquisa, foi o propósito organizacional, uma prática empresarial que emergiu posteriormente ao tema declaração de missão. No campo acadêmico, é reduzido o número de estudos sobre este último tema, ainda que se tenha identificado que a 
declaração de propósito seja uma prática empresarial. Das empresas certificadas pelo B Corp, do Brasil, identificou-se que 19\% das empresas pesquisadas possuem declaração pública do propósito.

A análise da declaração de missão organizacional considerou o tamanho médio das declarações e a presença ou não das categorias propostas pela literatura sobre o tema. A pesquisa mostrou que todas as declarações de missão das empresas estudadas apresentam uma das categorias de missão recomendadas pela literatura, mesmo que de maneira indireta. Quanto ao tamanho, identificou-se que as declarações mais extensas perdem o foco de uma declaração eficaz de missão, apresentando um texto redundante. Quanto às declarações mais curtas, essas são muito sucintas e também não transmitem uma declaração eficaz.

A análise das declarações de propósito, a partir da presença ou não de categorias que compõem essas declarações, conforme literatura pesquisada, possibilitou identificar que $19 \%$ das empresas estudadas possuem essa declaração pública. Este percentual ainda é baixo, considerando que as empresas B Corp possuem o propósito como base de sua existência. Os resultados da pesquisa mostram que a sustentabilidade foi a categoria que apresentou a média mais elevada de presença na declaração de propósito; essa categoria é um dos pilares das empresas B Corp.

A pesquisa sobre a presença ou a ausência das categorias que compõem as declarações de missão organizacional e do propósito organizacional por empresas certificadas B Corporation, do Brasil, mostrou a necessidade de consistência entre essas duas mensagens.

Quanto às implicações práticas deste estudo, destacam-se as contribuições para o trabalho de gestores referente à elaboração e à revisão da consistência das declarações de missão e propósito das organizações. Como limitação da pesquisa, este estudo analisou as empresas B Corp do Brasil. Sugere-se o estudo das declarações de missão organizacional e propósito organizacional a outros grupos de empresas, incluindo estudos 
comparativos e que analisem a consistência também entre essas declarações e as declarações de visão de futuro e de valores organizacionais.

\section{Referências}

Araújo, F. N. M. de. (2016). Interfaces entre Missão, Propósito e Comportamento Servidor nas Empresas de Serviços (Dissertação de Mestrado em Administração). Universidade Potiguar, Natal, Pernambuco, Brasil.

Bart, C. K. (2006). Mission statement quality and financial performance. European Management Journal, 24(1), 86-94. https://doi.org/10.1016/j.emj.2005.12.010

B Corporation. (2018). What are B Corps? B Corporation. Recuperado de https://bcorporation.net/about-b-corps

Campbell, A. (1992). The power of mission: aligning strategy and culture. Planning Review, 89(12), 94-102. https://doi.org/10.1108/eb054369

Campbell, A. (1997). Mission Statements. Long Range Planning, 30(6), 931932. https://doi.org/10.1016/S0024-6301(97)00084-8

Champy, J. \& Nohria, N. (2000). The Arc of Ambition - Defining the Leadership Journey. Cambridge, MA: Perseus Books.

Cochran, D. S.; David, F. R.; Gibson, C. K. (2008). A framework for developing an 383 effective mission statement. Journal of Business Strategies, 25(2), 27-39.

Comini, G., Fidelholc, M., Rodrigues, J. (2014, outubro) Empresas B: Princípios e desafios do Movimento B Corp. Anais dos Seminários em Administração - SEMEAD, Universidade de São Paulo (USP), São Paulo, SP, Brasil, 17.

David, F. R. \& David, F. R. (2003). It's time to redraft your mission statement. Journal of Business Strategy, 24(1), 11-14. https://doi.org/10.1108/02756660310508218

Drucker, P. (2006). What executives should remember. Harvard Business Review, February, 144-152.

Ellsworth, R. R. (2002). Leading with Purpose - The New Corporate Realities. Stanford, CA: Stanford University Press. 
George, B. (2003). Authentic Leadership - Rediscovering the Secrets to Creating Lasting Value. San Francisco, CA: Jossey-Bass.

Gilbert, J. (2010). Perspectives: what eBay's court fight with Craigslist reveals. B Corp NonprofitSoap Box. Recuperado de http://bcorp.nonprofitsoapbox.com/component/content/article/12-blog/247perspectiveswhat-ebays-court-fight-with-craigslist-reveals-by-jay-coengilbert.

Irigaray, H. A. R. \& Harten, B. A. (2014, maio). Missão Organizacional: Por Uma Análise de Sua Dimensão Simbólica. Anais do Encontro de Estudos Organizacionais da ANPAD, Gramado, Rio Grande do Sul, Brasil, 8.

Khalifa, A. S. (2012). Mission, purpose, and ambition: redefining the mission statement. Journal of Strategy and Management, 5(3), 236-251.

https://doi.org/10.1108/17554251211247553

King, D.L., Case, C.J., \& Premo, K.M. (2012). An International Mission Statement Comparsion: United States, France, Germany, Japan, and China. Academy of Strategic Management Journal, 11(2), 93-119.

Machado, H. V. (2003). A identidade e o contexto organizacional: perspectivas de análise. Revista de Administração Contemporânea (RAC). 51(73), 51-73. https://doi.org/10.1590/S1415-65552003000500004

Mintzberg, H, Ahlstrand, B., \& Lampel, J. (2000). Safári de Estratégia. Porto Alegre: Bookman.

Mullane, J. V. (2002). The mission statement is a strategic tool: when used properly. Management Decision, 40(5), 448-455. https://doi.org/10.1108/00251740210430461

Mussoi, A, Lunkes, R. J., \& Silva, R. V. (2011). Da Missão institucional: uma análise da efetividade e dos principais elementos presentes nas missões de empresas brasileiras de capital aberto. REGE Revista de Gestão (USP), 18(3), 361-384. https://doi.org/10.5700/rege431

Porter, M. \& Kramer, M. (2011). Creating Shared Value. Harvard Business Review, 89(1/2), 62-77.

Ready, D. A. \& Truelove, E. (2011). The power of collective ambition. Harvard Business of Strategy and Management, 5(3), 236-251.

Sisodia, R. (2009). Doing Business in the Age of Conscious Capitalism. Journal of Indian Business Research, 1(2/3), 188-192. 
https://doi.org/10.1108/17554190911005354

Stallworth, W. L.(2008). The mission statement: a corporate reporting tool with a past, present, and future. Journal of Business Communication, 45(2), 94-119. https://doi.org/10.1177/0021943607313989

Sufi, T. \& Lyons, H. (2003). Mission statements exposed. International Journal of Contemporary Hospitality Management, 15(5), 255-262. https://doi.org/10.1108/09596110310482173

Thompson Jr, A. A., Strickland II, A. J., \& Gamble, J. E. (2008). Administração estratégica. São Paulo: McGraw-Hill. 